\title{
Gestão de Pessoas na Administração Pública: Sistema de Carreira de Municípios Paranaenses
}

People Management in the Public Administration: Career System of Municipalities of the Parana State

Recebimento: 27/09/2019 - Aceite: 06/03/2020- Publicação: 01/08/2020

Processo de Avaliação: Double Blind Review

Juceli Fatima de Lara Medeiros ${ }^{1}$

Especialista em Gestão da Informação e do Conhecimento e Administração Pública

Municipal pela Universidade Estadual do Centro Oeste (UNICENTRO)

jucelimedeiros@hotmail.com

Fernando Zatt Schardosin

Doutorando em Administração pela Universidade do Estado de Santa Catarina (UDESC)

http://orcid.org/0000-0003-2956-3010

ferzatt@gmail.com

\section{RESUMO}

Este trabalho busca identificar se o sistema de carreira do quadro técnico administrativo de prefeituras municipais do Paraná produz resultados na busca pelo desenvolvimento profissional, como sugere o moderno modelo de gestão pública. Portanto o objetivo deste artigo é estabelecer uma análise do sistema de carreira de municípios entendendo a importância atribuída ao servidor público quanto à promoção na carreira. Especificamente buscou-se (1) investigar o atendimento pelo poder público das normas que regem a temática à luz da Administração Pública Gerencial; (2) mensurar o quantitativo de servidores alocados nos municípios e os índices de gastos com pessoal. A pesquisa apresenta o engessamento da máquina pública, na extrapolação dos limites com pessoal, inviabilizando avanços na carreira, desvalorização do servidor e falta de atendimento de normas pertinentes a matéria.

Palavras-chave: Índice de gastos; motivação; satisfação.

\section{ABSTRACT}

${ }^{1}$ Autor para correspondência: Rua Salvatore Renna, 875 - Santa Cruz, Guarapuava - PR, 85015-430 - Brasil.

Revista ENIAC Pesquisa, Guarulhos (SP), V.9, n.2, ago.2020-jan.2021 
This paper seeks to identify if the career system of the administrative technical staff of councils of Paraná produces results in the search for professional development, as the modern model of public management suggests. Therefore, the purpose of this article is to establish an analysis of the municipal career system, understanding the importance given to the public servant in career promotion. Specifically, it was sought to (1) investigate the attendance by the public authority of the norms that govern the subject in the light of the Public Management; (2) to measure the number of public servants allocated in the municipalities and the indices of personnel expenses. The research presents the machining of the public, in the extrapolation of limits with personnel, making unfeasible advances in the career, devaluation of the server and lack of compliance with norms pertinent to the matter.

Keywords: Index of expenses, motivation, satisfaction.

\section{INTRODUÇÃO}

A Administração Pública no Brasil vem sofrendo importantes transformações com a introdução de reformas administrativas que se sucedem no tempo, buscando acima de tudo a modernização da gestão, visando, banir o favorecimento e interesse pessoal. Porém, está longe de se alcançar resultados totalmente positivos, visto que são práticas viciosas que influenciam diretamente na gestão, e assim o país permanece convivendo de forma simultânea com os modelos patrimonialista, burocrático e gerencial.

Um modelo de reforma positivo e efetivo é a Emenda Constitucional n. ${ }^{\circ}$ 19/98 que se materializou como uma das grandes heranças do gerencialismo no Brasil, focando na eficiência do serviço público, prestação de serviços de qualidade e atendimento aos anseios da coletividade (BRASIL, 2017).

A modernização da gestão exige uma nova cultura gerencial, orientada para resultados e flexibilização administrativa, especialmente na área de pessoal, que busca o aperfeiçoamento das capacidades gerenciais, e a nova gestão pública supre tais exigências, contribuindo com a profissionalização e valorização do servidor público, formulando políticas que permeiam desde a captação de novos servidores, desenvolvimento, sistema remuneratório adequado, até a instituição de carreiras compatíveis com as necessidades do Estado moderno (BRESSER, 1995). 
Assim para explorar esta temática foram escolhidos os municípios da Cantuquiriguaçu (Cantu) como é conhecida, sendo uma associação situada no médio centro oeste do estado do Paraná, fundada em 08 de agosto de 1984 e composta por 21 (vinte e um) municípios (CANTUQUIRIGUAÇU, 2017).

Nem sempre os municípios conseguem se organizar de forma eficaz, seja pela má gestão de recursos financeiros, seja pelo inchaço da máquina pública, comprometendo sua realidade financeira, e o que se espera de um sistema de carreira desenvolvido, efetivo e consistente, capaz de promover o servidor de fato não acontece.

Neste enfoque, a observância aos limites com pessoal no setor público estabelecidos pela Constituição Federal de 1988 e Lei Complementar n 101/2000 (Lei de Responsabilidade Fiscal - LRF), deve receber tratamento especial por parte do gestor, atentando-se quanto a não extrapolação dos limites de alerta $(48,60 \%)$ e/ou prudencial $(51,30 \%)$ do teto posto ao Executivo Municipal de 54\% sobre a Receita Corrente Líquida do município. Caso o gestor extrapole os limites definidos, o excedente terá de ser eliminado em prazos fixados, vedando-se qualquer aumento de despesa com pessoal, inclusive alteração de estrutura de carreira (TOLEDO E ROSSI, 2001).

Assim, o objetivo deste estudo é traçar uma análise do sistema de carreira dos municípios da Cantu, visando verificar a importância atribuída ao servidor público municipal no que se refere à promoção na carreira. Especificamente pretende-se investigar o atendimento por parte do poder público às normas que regem a temática à luz da administração pública gerencial. Mensurar o quantitativo de servidores lotados nos municípios e o índice de gastos com pessoal, para avaliar a efetividade da ação governamental.

A boa gestão depende essencialmente de pessoas preparadas, pautadas no planejamento e nos princípios constitucionais e do direito administrativo, orientada segundo Dagnino (2009) na transição do "Estado Herdado" para o "Estado Necessário" que seja capaz de atender às demandas presentes e satisfazer novas, aliando a capacidade de elaborar políticas públicas à atuação eficiente e eficaz no uso de recursos públicos.

Em relação a pesquisa, se torna importante para investigações de carreiras públicas, como ferramenta para evitar os reducionismos das políticas de gestão de pessoas de outras áreas, cujas especificidades diferem do tema em estudo, assim como as dinâmicas 
motivacionais e institucionais de organizações e carreiras deste setor (KLEIN e MASCARENHAS, 2016).

\section{REVISÃO DA LITERATURA}

A Constituição Federal de 88 dispõe que a atividade administrativa no âmbito do poder público em todas as esferas de governo orienta-se pelos princípios constitucionais que regem a Administração Pública: legalidade, impessoalidade, moralidade, publicidade e eficiência (BRASIL, 2008).

Para cumprir sua função social, o Estado precisou se remodelar e segundo Salm e Menegasso (2009) a Administração Pública convencional deu lugar à Nova Gestão Pública ou Gestão Pública Gerencial, vez que o modelo anterior era incapaz de produzir a contento os serviços públicos, surgindo, então um movimento de reforma do Estado como resposta às deficiências do modelo convencional, visando acima de tudo à modernização da gestão, orientada para resultados.

A evolução da gestão sugere mudanças nas formas de conceber as organizações e como cita Bendassolli (2009) são seguidas (ou acompanhadas) de novos modelos de carreira que para a sua construção e das práticas de gestão, demandam estruturas mais flexíveis, menos hierarquizadas, orientadas para o conhecimento, dependentes de criatividade e de outras competências softs onde a área de recursos humanos deve se posicionar como uma facilitadora do desenvolvimento individual, não deixando dúvida de que os modelos emergentes de carreira ajudarão nesse reposicionamento institucional do campo de gestão de pessoas.

\subsection{Contextualização e propostas da área de Gestão de Pessoas}

O modelo de gestão no contexto das organizações vem mudando, principalmente na área de gestão de pessoas. O que antes era restrito a execução de funções rotineiras de Recursos Humanos, hoje é mais estratégico. Criando uma cultura organizacional de vanguarda em relação às melhores práticas de gestão (ZAMPIER, et al, 2013). Tais práticas ganharam conotações diversas: Administração de Pessoal, Administração de Recursos Humanos e Gestão de Pessoas. 
A Administração de Pessoal tem função apenas administrativa e de controle funcional, sem motivação (OLIVEIRA e MEDEIROS, 2011). Já a Administração de Recursos Humanos envolve decisões que formam as relações de trabalho e sua qualidade influencia diretamente a capacidade da organização e de seus empregados em atingir seus objetivos (MILKOVICH e BOUDREAU, 2000). Por fim, a área de gestão de pessoas surgiu da necessidade de regência das relações de trabalho, e segundo Oliveira e Medeiros (2011) soa mais nobre do que administração que expressa uma ideia de trato com coisas materiais, enquanto Gestão de Pessoas cuida das pessoas e estimula o seu desenvolvimento como ser humano.

$\mathrm{O}$ atual modelo trouxe para a área de gestão de pessoas algumas propostas, descritas por Junquilho (2010), como: qualidade no serviço público, foco no atendimento às necessidades e expectativas do cidadão, profissionalização do servidor público, elevado grau de eficiência na utilização dos recursos disponíveis, controle dos gastos públicos, bem como responsabilização das ações do gestor.

\subsection{Planejamento de Gestão de Pessoas}

Tachizawa, Ferreira e Fortuna (2001, p. 129) citam que "o planejamento da gestão de pessoas é um processo de decisão antecipado a respeito das pessoas necessárias para que uma organização concretize os seus propósitos econômico-financeiros dentro de determinado período.

Marconi (2005) sintetiza as políticas de gestão de pessoas como: uma estrutura de carreira que estimule o servidor a capacitar-se e aprimorar seu desempenho como forma de assumir novas responsabilidades; uma estrutura salarial composta de incentivos remuneratórios e benefícios que estimule o servidor no cargo, e; uma estrutura de avaliação que possibilite verificar o seu desempenho e as necessidades de capacitação associada à sua progressão.

Para estruturar as políticas de gestão de pessoas, faz-se necessário assentá-las em conformidade com a estrutura organizacional, a começar pelo plano de cargos e salários, ao qual será vinculado o plano de carreira, avaliação de desempenho e treinamento e desenvolvimento de pessoal. Estudos demonstram a necessidade de uma avaliação de desempenho condizente com o estimulo ao aprimoramento profissional, reduzindo a 
importância relativa de critérios como antiguidade, por exemplo (FILHO e PESSOA, 2011).

Um ponto crucial, é a administração de cargos e salários a qual deu origem aos planos, que de acordo com Zampier et al (2013) configura-se como um conjunto de regras e normas, que estabelece os mecanismos de gestão de pessoas. Sendo importantes instrumentos de gestão para questões relacionadas com remuneração e carreira profissional na organização.

Stefano (2011) cita que um fator que desponta como o mais importante neste contexto, corresponde à compensação que a organização oferece ao colaborador pelo serviço prestado em dado período, somando-se salários, benefícios e outras vantagens. Logo a potencial satisfação do colaborador vinculada às atividades da organização resulta na condição fundamental para a fixação das políticas de gestão de pessoas.

\subsection{A Administração de Carreiras como instrumento de Gestão no Setor Público}

Quando se trata de planejamento e desenvolvimento de carreira, Dutra (1996) afirma que a administração de carreira é a resposta mais completa para as necessidades da organização na gestão de seu pessoal. London e Stumph (1982) definem carreira como uma sequência de posições, ao longo da vida profissional, o que inclui estágios refletindo as necessidades, motivos, aspirações dos indivíduos, também inclui as expectativas e imposições da organização e da sociedade.

Tachizawa, Ferreira e Fortuna (2001) destacam que este organismo resulta no contínuo desenvolvimento das pessoas e ao mesmo tempo ao alcance dos objetivos e estratégias organizacionais. O desenvolvimento do corpo funcional se dá por meio do Plano de Carreira, que de acordo com Stefano (2011, p. 31) é a “determinação da sequência ótima da carreira, definindo as alternativas de oportunidades possíveis dentro da organização". Primak et al (2014, p. 5) lembram que "um plano de carreira deve motivar o funcionário a buscar novos conhecimentos dentro de sua área profissional", além disso, aumenta a produtividade e a qualidade dos serviços prestados. É uma espécie de guia, de norte que estabelece formas para alcançar os objetivos desejados na profissão escolhida, seguindo uma rota, um percurso. 
Dutra (1996) relaciona plano de carreira ou sistema de carreira a uma "estrutura" que em suma tem a função de estabelecer e organizar o conjunto de expectativas que a organização tem em relação às pessoas que nela trabalham, atrelada aos níveis de valorização e capacitação. Esta estrutura, no sentido de criar e entender planos e sistemáticas para avaliar a qualidade e adequação dos recursos humanos, envolve a progressão horizontal, a promoção vertical, a avaliação de desempenho e o treinamento e desenvolvimento, vez que são institutos de desenvolvimento na carreira.

Progressão na carreira é o enriquecimento horizontal do cargo a partir do aperfeiçoamento das aptidões do servidor na função, que passa de uma referência salarial para outra e promoção é o enriquecimento vertical do cargo, significando a assunção de responsabilidade de nível hierárquico de tarefas mais alto e ocorre alternadamente, por mérito e tempo, passando de uma classe para outra (PARANÁ, 2018).

Importante instrumento constitucional de controle da eficácia do serviço público e consequentemente do processo de carreira é a avaliação de desempenho, instituída pela emenda constitucional $\mathrm{n}^{\mathrm{o}} 19$ de 1998 e de obrigatória observância pelo administrador, permitindo verificar quanto o profissional se adapta aos objetivos da organização e as demandas e exigências do trabalho (BRASIL, 2017). Marras (2009) apud Zampier (2013) ressalta que com este instrumento de gestão é possível mensurar três campos organizacionais: resultados, conhecimento e comportamento.

Por fim, e não menos importante, tem-se o treinamento e desenvolvimento, que segundo Milkovitch e Boudreau (2010) o primeiro visa promover a aquisição de habilidades, conceitos ou atitudes que resultem em uma melhoria da adequação entre as características do pessoal e as exigências dos papéis funcionais e o segundo tende a aperfeiçoar a longo prazo as capacidades e motivações dos funcionários a fim de torná-los futuros membros valiosos da organização, que inclui além do treinamento, a carreira e outras experiências.

\section{METODOLOGIA}

Para se alcançar os objetivos propostos, realizou-se um estudo e investigação de campo, caracterizando uma pesquisa descritiva de caráter exploratório, visando à obtenção 
de informações que possam apontar o comportamento dos sistemas de carreira do quadro técnico administrativo das prefeituras da região Cantuquiriguaçu, no estado do Paraná.

No que se refere ao processo, à pesquisa apresenta caráter descritivo qualitativo, voltada ao levantamento de dados de natureza primária realizado no mês de fevereiro do ano de 2018, por meio de questionário com questões de múltipla escolha, sendo este autoexplicativo, dirigido ao departamento de pessoal de cada entidade, via correio eletrônico e devolvido pelo mesmo canal de comunicação para tabulação.

É oportuno ressaltar que a tentativa de censo teve como universo amostral 21 (vinte e um) municípios da Cantuquiriguaçu: Campo Bonito, Candói, Cantagalo, Catanduvas, Diamante do Sul, Espigão Alto do Iguaçu, Foz do Jordão, Goioxim, Guaraniaçu, Ibema, Laranjeiras do Sul, Marquinho, Nova Laranjeiras, Palmital, Pinhão, Porto Barreiro, Quedas do Iguaçu, Reserva do Iguaçu, Rio Bonito do Iguaçu, Três Barras do Paraná e Virmond, dos quais se alcançou uma amostragem não probabilística de 8 (oito) respondentes. Apesar da baixa incidência de respostas a pesquisa não foi comprometida, e o foco, que tinha como campo experimental o departamento de pessoal das prefeituras por se tratar do setor que detém as informações, foi alcançado. Além disso, foram explorados sítios eletrônicos dos municípios respondentes, visando mapear e extrair dados que pudessem dar suporte para a comprovação das hipóteses.

O questionário foi dividido em duas partes de aplicações simultâneas: a primeira com 9 (nove) questões para conhecer o perfil dos respondentes (profissionais da área) sem necessidade de identificação, bem como a estrutura administrativa, e a segunda composta por 20 (vinte) questões para investigar o cenário atual do sistema de carreira. Para os resultados foram atribuídos critérios e valores de escala para cada posição, conforme segue: Não adota a prática - valor 1,0; Pretende adotar a prática - valor 2,0; Adota em menor parte a prática - valor 3,0; Adota em grande parte a prática - valor 4,0, e; Adota totalmente a prática - valor 5,0 .

Considerando que as questões seguem uma estrutura formal por agrupamentos, baseadas em 3 (três) subsistemas, estas foram agrupadas em conformidade com as especificidades locais, já que todos são municípios de pequeno porte. Para facilitar a tabulação e descrição dos resultados, este estudo foi estruturado em 5 (cinco) tópicos acompanhado das políticas de gestão: (1) Perfil dos respondentes; (2) Perfil das organizações; (3) Subsistema de aplicação de pessoas - (3.1) Administração de cargos e 
(3.2) Planejamento de carreira e Avaliação de desempenho; (4) Subsistema de manutenção de pessoas - (4.1) Administração de salários, e; (5) Subsistema de desenvolvimento de pessoas - (5.1) Treinamento e desenvolvimento de pessoal.

\section{ANÁLISE DE DADOS E RESULTADOS}

Para computação e análise dos dados coletados foi utilizada planilha eletrônica, partindo-se de um raciocínio hipotético-dedutivo, os quais passaram a ser organizados e sintetizados em gráficos, tabelas, quadros ou qualquer outro meio que pudesse acomodar os números contabilizados. A amostragem abrangeu (8) instituições representativas do universo amostral composto por (21) municípios, representando 38\% de uma população para qual os resultados são generalizados, e não se buscou estudar casos isolados e sim comuns a todos.

\subsection{Perfil dos respondentes}

A tabulação dos dados iniciou-se com a pesquisa de apoio no que se refere ao gênero, seguida de cinco fatores que se sucedem (faixa etária, grau de escolaridade, tipo de cargo, tempo de experiência no cargo e faixa salarial), na forma da Tabela 1.

TABELA 1: Perfil dos respondentes

\begin{tabular}{|c|c|c|c|}
\hline Variável & Tipo & Quantidade & Percentual (\%) \\
\hline \multirow{2}{*}{ Gênero } & Feminino & 6 & $75,0 \%$ \\
\hline & Masculino & 2 & $25,0 \%$ \\
\hline \multirow{4}{*}{ Faixa Etária } & 18 a 28 anos & 1 & $12,5 \%$ \\
\hline & 29 a 39 anos & 1 & $12,5 \%$ \\
\hline & 40 a 50 anos & 2 & $25,0 \%$ \\
\hline & 51 a 61 anos & 4 & $50,0 \%$ \\
\hline \multirow{2}{*}{ Escolaridade } & Ensino Superior Completo & 6 & $75,0 \%$ \\
\hline & Ensino Superior Incompleto & 2 & $25,0 \%$ \\
\hline \multirow{2}{*}{ Tipo de Cargo } & Efetivo & 6 & $75,0 \%$ \\
\hline & Comissão & 2 & $25,0 \%$ \\
\hline \multirow{3}{*}{$\begin{array}{c}\text { Tempo de experiência na } \\
\text { área de atuação }\end{array}$} & Até 10 anos & 4 & $50,0 \%$ \\
\hline & De 21 a 30 anos & 2 & $25,0 \%$ \\
\hline & Acima de 30 anos & 2 & $25,0 \%$ \\
\hline \multirow{4}{*}{ Faixa salarial (R\$) } & Até R\$ $2.000,00$ & 2 & $25,0 \%$ \\
\hline & De $R \$ 2.001,00$ a R\$ $3.000,00$ & 3 & $37,5 \%$ \\
\hline & De $R \$ 3.001,00$ a R\$ $4.000,00$ & 1 & $12,5 \%$ \\
\hline & Acima de RS $4.000,00$ & 2 & $25,0 \%$ \\
\hline
\end{tabular}

Fonte: Dados da Pesquisa. 
Das informações coletadas, infere-se que a área de Recursos Humanos das instituições respondentes opera com predominância feminina. Em relação ao fator idade, metade, são pessoas mais velhas que tem entre 51 a 61 anos. Quanto ao grau de escolaridade, ficou demonstrado que os respondentes têm ou estão cursando ensino superior. Os cursos universitários informados variam entre Gestão Pública, Políticas Públicas, Ciências Contábeis, Administração e Direito.

Outro fator pesquisado faz alusão ao tipo de cargo (se efetivo ou comissão) ocupado pelo detentor da pasta, sendo que $75 \%$ são servidores efetivos. O fator tempo de experiência na área mostrou que a 50\% das prefeituras respondentes atuam com servidores com menor experiência em RH, ou seja, de até 10 (dez) anos. Em relação a variável salário, somente $25 \%$ dos respondentes recebe acima de $\mathrm{R} \$ 4.000,00,37,5 \%$ até $\mathrm{R} \$$ $3.000,00$ e 12,5\% até $\mathrm{R} \$ 4.000,00$, o restante até $\mathrm{R} \$ 2.000,00$.

\subsection{Perfil das organizações}

A tabela a seguir apresenta dados da estrutura organizacional que será a fração necessária para dar entendimento e precisão à segunda parte da pesquisa, que é a investigação.

A Tabela 2 mostra que 37,5\% das prefeituras empregam acima de 401 servidores e o mesmo percentual de 201 a 300 servidores. A pesquisa demonstrou que todos os respondentes, extrapolaram seu índice de gasto com pessoal em 2017, seja em relação ao limite de alerta, seja em relação ao limite prudencial, isto é $75 \%$ gastou de 46 a $50 \%$ e $25 \%$ entre 51 a $55 \%$. 
TABELA 2: Perfil das Organizações

\begin{tabular}{|c|c|c|c|}
\hline Variável & Tipo & Quantidade & $\begin{array}{l}\text { Percentual } \\
(\%)\end{array}$ \\
\hline \multirow{3}{*}{ Total de servidores } & De 201 a 300 pessoas & 3 & $37,5 \%$ \\
\hline & De 301 a 400 pessoas & 1 & $12,5 \%$ \\
\hline & Acima de 401 & 3 & $37,5 \%$ \\
\hline \multirow{2}{*}{$\begin{array}{c}\text { Índice de gastos com } \\
\text { pessoal em } 2017\end{array}$} & De 46 a $50 \%$ & 6 & $75,0 \%$ \\
\hline & De 51 a $55 \%$ & 2 & $25,0 \%$ \\
\hline \multirow{4}{*}{ Tipo de Plano } & Plano de Classificação de Cargos & 1 & $12,5 \%$ \\
\hline & $\begin{array}{l}\text { Plano de Cargos com Plano de Carreira } \\
\text { integrado }\end{array}$ & 5 & $62,5 \%$ \\
\hline & $\begin{array}{l}\text { Plano de Cargos com Plano de Carreira em } \\
\text { separado }\end{array}$ & 1 & $12,5 \%$ \\
\hline & Outro & 1 & $12,5 \%$ \\
\hline
\end{tabular}

Fonte: Dados da Pesquisa.

A partir das informações apresentadas procurou-se conhecer os índices exatos de gastos com pessoal no exercício, buscando nos Relatórios de Gestão Fiscal dos municípios nos termos da lei de responsabilidade fiscal. O Gráfico 1 comprova a extrapolação, demonstrando que a maioria $(75 \%)$ está a iminência de atingir o limite prudencial e os demais municípios (25\%) estão rumo a atingir o limite máximo.

GRÁFICO 1: Índice de Gastos com Pessoal

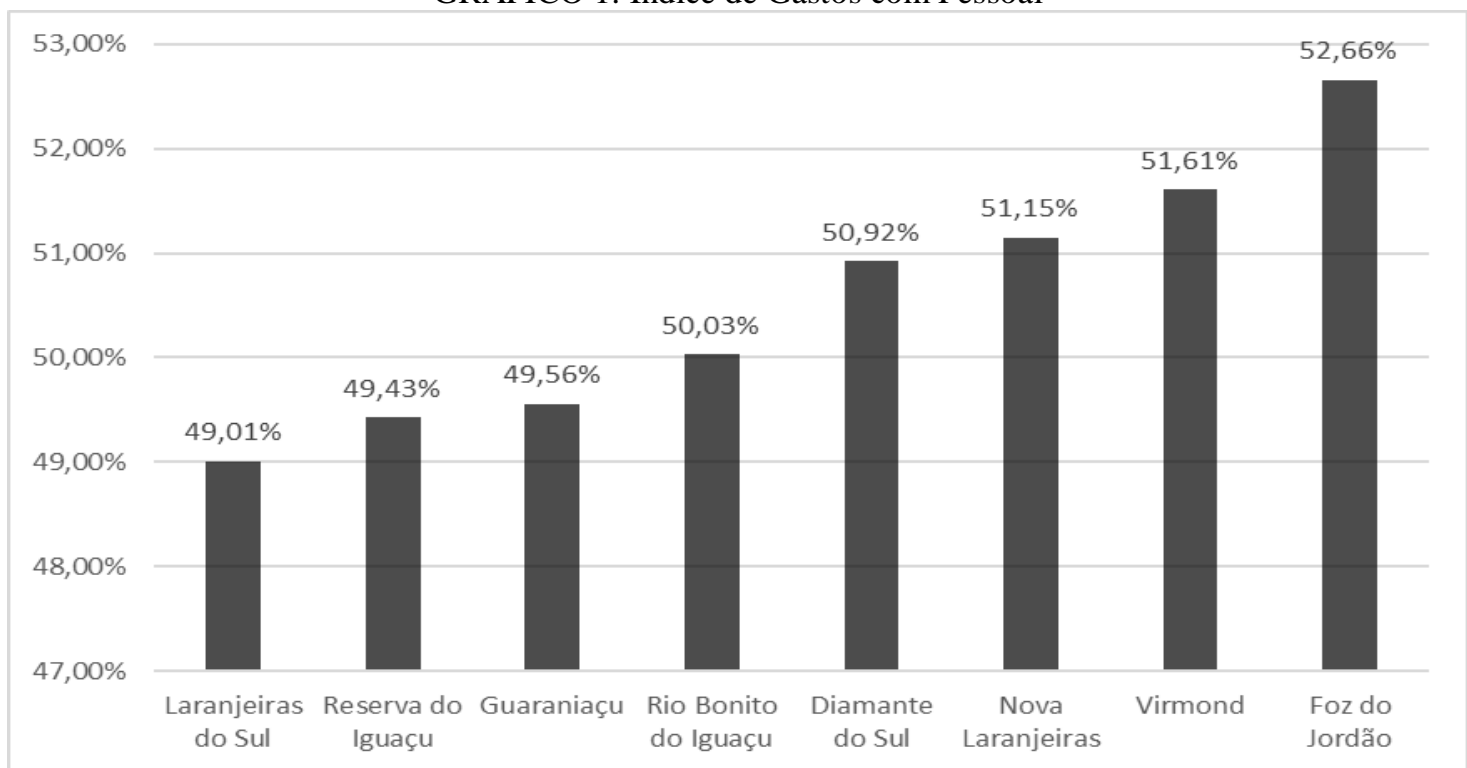

Fonte: elaborada pelos autores com base nos relatórios de gestão fiscal.

Em razão do eventual excesso de pessoal no setor público, foi perguntado na pesquisa investigatória, mas, que por conveniência, foi vinculada a esta questão, se os municípios identificam antes de abrir concurso público o quantitativo necessário de pessoal 
por secretaria, descrevendo as tarefas, atribuições e requisitos de investidura no cargo, e $50 \%$ afirmou adotar totalmente a prática e os demais 50\% dividiram-se entre empregar a prática em grande e menor parte. A última questão relacionada à estrutura administrativa demonstrou que 62,5\% dos municípios respondentes possuem Plano de Cargos com Plano de Carreira integrado, 12,5\% tem plano de carreira separado do plano de cargos e 12,5\% possui somente plano de classificação cargos.

\subsection{Subsistema de aplicação de pessoas}

\subsubsection{Administração de Cargos}

Iniciando a segunda parte da pesquisa referente à investigação, mas, buscaram-se elementos que pudessem subsidiar o objetivo do estudo, onde foi perguntado sobre à estruturação do plano de cargos com base em normas que estabeleçam os mecanismos da área de gestão de pessoas, vez que a carreira pressupõe cargos, e constatou-se que somente $37,5 \%$ dos municípios estão totalmente estruturados, $12,5 \%$ estão em grande parte estruturados, $12,5 \%$ em menor parte e $37,5 \%$ não tem nenhuma estrutura de plano de cargos.

\subsubsection{Planejamento de Carreira e Avaliação de Desempenho}

As informações obtidas através da pesquisa mostram que da parcela de instituições que dispõe de Plano de Carreira seja integrado ao de cargos ou separado, somente 37,5\% encontra-se totalmente estruturada em sucessão de posições no cargo, outras $25 \%$ estão divididas em partes iguais entre estar estruturadas em menor e maior parte. Enquanto que, 37,5\% não se estruturou. Outro fator preocupante é o índice baixo de instituições que revisam e atualizam regularmente o Plano de Carreira, ou seja, somente $12,5 \%$ tem este hábito integralmente, outras $12,5 \%$ adotam em grande parte a prática, 37,5\% em menor parte. A pesquisa demonstrou ainda que somente $12,5 \%$ tem total preocupação em criar oportunidades de movimentação vertical na carreira, à chamada promoção. Já $25 \%$ tem grande preocupação com esta questão e 12,5\% preocupa-se, porém, em menor grau, 
enquanto as demais instituições ainda não adotam a pratica. Ainda, da parcela de instituições que oferece promoção na carreira, $75 \%$ consegue mantê-las em dia.

TABELA 3: Planejamento de Carreira e Avaliação de Desempenho

\begin{tabular}{|c|c|c|c|c|c|}
\hline \multirow[t]{2}{*}{ Variáveis } & $\begin{array}{l}\text { Não adota } \\
\text { a prática }\end{array}$ & $\begin{array}{l}\text { Pretende } \\
\text { adotar a } \\
\text { prática }\end{array}$ & $\begin{array}{l}\text { Adota em } \\
\text { menor } \\
\text { parte a } \\
\text { prática }\end{array}$ & $\begin{array}{l}\text { Adota em } \\
\text { grande } \\
\text { parte a } \\
\text { prática }\end{array}$ & $\begin{array}{l}\text { Adota } \\
\text { totalmente } \\
\text { a prática }\end{array}$ \\
\hline & $\%$ & $\%$ & $\%$ & $\%$ & $\%$ \\
\hline $\begin{array}{l}\text { Conta com Plano de Carreira contendo a } \\
\text { sucessão de posições no cargo com a devida } \\
\text { valorização e requisitos de acesso. }\end{array}$ & 25,0 & 12,5 & 12,5 & 12,5 & 37,5 \\
\hline $\begin{array}{l}\text { Revisa e atualiza com frequência o Plano de } \\
\text { Carreira no decorrer dos anos conforme } \\
\text { normas especificas atualizadas. }\end{array}$ & 25,0 & 12,5 & 37,5 & 12,5 & 12,5 \\
\hline $\begin{array}{l}\text { Cria oportunidades possiveis de progresso } \\
\text { (movimentação vertical/promoção na } \\
\text { carreira), para o servidor. }\end{array}$ & 37,5 & 12,5 & 12,5 & 25,0 & 12,5 \\
\hline $\begin{array}{l}\text { Mantem em dia as promoções adquiridas, } \\
\text { obedecendo prazos e demais requisitos } \\
\text { previamente fixados. }\end{array}$ & 12,5 & 12,5 & 25,0 & 12,5 & 37,5 \\
\hline $\begin{array}{l}\text { Deixa de realizar promoção de servidor em } \\
\text { decorrência de excesso de gasto com } \\
\text { pessoal. }\end{array}$ & 50,0 & 0,0 & 37,5 & 12,5 & 0,0 \\
\hline $\begin{array}{l}\text { Oferece condições de progressão horizontal } \\
\text { (mobilidade lateral) no sentido de } \\
\text { movimento de crescimento da escala de } \\
\text { salário. }\end{array}$ & 12,5 & 12,5 & 37,5 & 12,5 & 25,0 \\
\hline Mantem em dia as progressões horizontais. & 12,5 & 25,0 & 12,5 & 25,0 & 25,0 \\
\hline $\begin{array}{l}\text { Cria e utiliza instrumentos de avaliação } \\
\text { individual de desempenho do servidor, com } \\
\text { atribuição de nota ou conceito, vinculada ao } \\
\text { alcance dos resultados organizacionais. }\end{array}$ & 12,5 & 37,5 & 12,5 & 12,5 & 25,0 \\
\hline $\begin{array}{l}\text { Comunica expressamente (feedback) ao } \\
\text { servidor os aspectos positivos e/ou } \\
\text { negativos do resultado da avaliação de } \\
\text { desempenho. }\end{array}$ & 25,0 & 37,5 & 25,0 & 0,0 & 12,5 \\
\hline
\end{tabular}

Fonte: Dados da Pesquisa.

Perguntou-se ainda se os municípios deixam de realizar promoção de servidor em decorrência do excesso de gasto com pessoal, e o resultado apontou que $50 \%$ dos respondentes alega não ser por conta deste motivo a falta de concessão de promoções, $37,5 \%$ atribui a este fator uma pequena parcela de sua omissão, e 12,5\% garante que esta é a grande razão.

Além das variáveis apresentadas, a tabela 3 mostra os dados obtidos em relação à progressão horizontal. A maioria dos respondentes afirmou oferecer condições de avanço ao servidor neste sentido, sendo que $25 \%$ adota totalmente a prática, 12,5\% adota em grande parte, $37,5 \%$ adota em menor parte, já 25\% não adota tal comportamento. Porém, 
de acordo com a pesquisa, somente $25 \%$ está com as progressões totalmente em dia, $25 \%$ está com grande parte dos avanços em dia e 12,5\% está com uma pequena parcela em dia. O restante não mantém esta rotina.

Fora analisado ainda a questão da avaliação de desempenho do servidor para conhecer se a organização cria e utiliza este instrumento para avaliar seu pessoal. Assim, foi constatado que 50\% adota a prática, seja de forma integral ou parcial, 37,5\% pretende adotá-la e $12,5 \%$ não adota. Para complementar a questão foi perguntado se a organização executa a retroalimentação, comunicando ao servidor pontos positivos e/ou negativos de seu resultado (feedback) e foi constatado que somente $12,5 \%$ dos respondentes adotam totalmente esta prática, $25 \%$ adota em menor parte e os demais não adotam.

\subsection{Subsistema de manutenção de pessoas - administração de salários}

A primeira questão procurou saber se a instituição constrói sua estrutura salarial em faixas salariais do agrupamento de cargos e 37,5\% delas afirmaram adotar totalmente a prática, 25\% adotam, mas, em menor parte e as demais não adotam. Quanto à definição da política de remuneração, 37,5\% dos municípios afirmaram adotar totalmente a prática, $12,5 \%$ adotam em grande parte, $25 \%$ adotam em menor parte, e os outros $25 \%$ não adotam.

Com base nas duas questões anteriores, foi perguntado se os municípios repõem as perdas inflacionárias sem deixar ocorrer defasagem salarial e 37,5\% afirmaram haver defasagem salarial. Somente $12,5 \%$ estão em dia, $25 \%$ procuram adotar em grande parte a prática de reposição e $25 \%$ em menor parte.

Revista ENIAC Pesquisa, Guarulhos (SP), V.9, n.2, ago.2020-jan.2021 
Tabela 4: Administração de Salários

\begin{tabular}{|c|c|c|c|c|c|}
\hline \multirow[t]{2}{*}{ Variáveis } & $\begin{array}{l}\text { Não adota } \\
\text { a prática }\end{array}$ & $\begin{array}{l}\text { Pretende } \\
\text { adotar a } \\
\text { prática }\end{array}$ & $\begin{array}{l}\text { Adota em } \\
\text { menor } \\
\text { parte a } \\
\text { prática }\end{array}$ & $\begin{array}{l}\text { Adota em } \\
\text { grande } \\
\text { parte a } \\
\text { prática }\end{array}$ & $\begin{array}{l}\text { Adota } \\
\text { totalmente } \\
\text { a prática }\end{array}$ \\
\hline & $\%$ & $\%$ & $\%$ & $\%$ & $\%$ \\
\hline $\begin{array}{l}\text { Constrói a estrutura salarial formando faixas } \\
\text { salariais do agrupamento de cargos, visando } \\
\text { atender sua política salarial. }\end{array}$ & 25,0 & 12,5 & 25,0 & 0,0 & 37,5 \\
\hline $\begin{array}{l}\text { Define a política de remuneração } \\
\text { determinando o salário base proposto, os } \\
\text { tipos de remuneração variável e os } \\
\text { beneficios sociais que formarão a } \\
\text { remuneração total. }\end{array}$ & 25,0 & 0,0 & 25,0 & 12,5 & 37,5 \\
\hline $\begin{array}{l}\text { Repõe as perdas inflacionárias sem deixar } \\
\text { ocorrer defasagem salarial. }\end{array}$ & 37,5 & 0,0 & 25,0 & 25,0 & 12,5 \\
\hline
\end{tabular}

Fonte: Dados da Pesquisa.

\subsection{Subsistema de desenvolvimento de pessoas - desenvolvimento de pessoal}

Prosseguindo a análise, foi perguntado se a organização identifica as necessidades individuais de capacitação durante o processo de avaliação de desempenho do servidor, bem como se propõe ações educacionais com base nas oportunidades de melhoria identificadas na avaliação de desempenho, além de oferecer outros incentivos que contribuam com o desenvolvimento na carreira, conforme se observa na tabela 5 .

Tabela 5: Treinamento e Desenvolvimento de Pessoal

\begin{tabular}{|l|c|c|c|c|c|}
\hline \multirow{2}{*}{ Variáveis } & Não adota & $\begin{array}{c}\text { Pretende } \\
\text { adotar a } \\
\text { prática }\end{array}$ & $\begin{array}{c}\text { Adota em } \\
\text { menor } \\
\text { parte a } \\
\text { prática }\end{array}$ & $\begin{array}{c}\text { Adota em } \\
\text { grande } \\
\text { parte a } \\
\text { prática }\end{array}$ & $\begin{array}{c}\text { Adota } \\
\text { totalmente } \\
\text { a prática }\end{array}$ \\
\cline { 2 - 6 } & $\mathbf{\%}$ & $\mathbf{\%}$ & $\mathbf{\%}$ & $\mathbf{\%}$ & $\mathbf{\%}$ \\
\hline $\begin{array}{l}\text { Identifica as necessidades individuais de } \\
\text { capacitação durante o processo de avaliação } \\
\text { de desempenho do servidor. }\end{array}$ & 50,0 & 25,0 & 12,5 & 0,0 & 12,5 \\
\hline $\begin{array}{l}\text { Propõe ações educacionais para o servidor } \\
\text { com base nas oportunidades de melhoria } \\
\text { identificadas na avaliação de desempenho. }\end{array}$ & 50,0 & 25,0 & 12,5 & 0,0 & 12,5 \\
\hline $\begin{array}{l}\text { Oferece outros incentivos para a capacitação } \\
\text { contínua do servidor (ex. bolsas de estudo, } \\
\text { incentivos para obtenção de certificação, } \\
\text { flexibilização da jornada de trabalho). }\end{array}$ & 50,0 & 0,0 & 25,0 & 12,5 & 12,5 \\
\hline
\end{tabular}


Em linhas gerais, $75 \%$ dos respondentes não adotam a prática de identificar necessidades de capacitação, $12,5 \%$ adota, mas, em menor grau e somente $12,5 \%$ adotam totalmente. Fora perguntado também se as instituições propõem ações educacionais para o servidor com base nas oportunidades de melhoria identificadas na avaliação de desempenho, e, portanto, como 75\% não tem o habito de identificar tais necessidades e $12,5 \%$ tem, mas, em menor grau, as mesmas não propõem ações educacionais, ficando por conta de $12,5 \%$ a adoção da prática. Nesta conjuntura, foi perguntado se o município oferece outros incentivos para a capacitação contínua do servidor, e, somente $12,5 \%$ se preocupa em oferecer tais incentivos, $12,5 \%$ afirma adotar em grande parte e $25 \%$ em menor parte. A outra metade, ou seja, 50\% não se preocupa com isso.

Para concluir a pesquisa e facilitar a análise das informações, isto é, agrupando todas as variáveis analisadas, optou-se por criar níveis de capacidade de gestão que ficou assim definido, conforme quadro 1.

Quadro 1: Nível de adoção da prática

\begin{tabular}{|l|c|c|c|c|}
\hline \multicolumn{2}{|c|}{ Prática ainda não adotada } & \multicolumn{3}{c|}{ Nível de adoção da prática } \\
\hline Não adota a prática & Pretende adotar a prática & $\begin{array}{c}\text { Adota em menor } \\
\text { parte a prática }\end{array}$ & $\begin{array}{c}\text { Adota em grande } \\
\text { parte a prática }\end{array}$ & $\begin{array}{c}\text { Adota totalmente } \\
\text { a prática }\end{array}$ \\
\hline \multicolumn{2}{|c|}{ Inexistente } & Inicial & Intermediário & Aprimorado \\
\hline
\end{tabular}

Fonte: Dados da Pesquisa.

A partir desta análise, infere-se que os municípios analisados estão com baixa capacidade de gestão, conforme gráfico 2:

Gráfico 2: Níveis de capacidade de gestão de pessoas

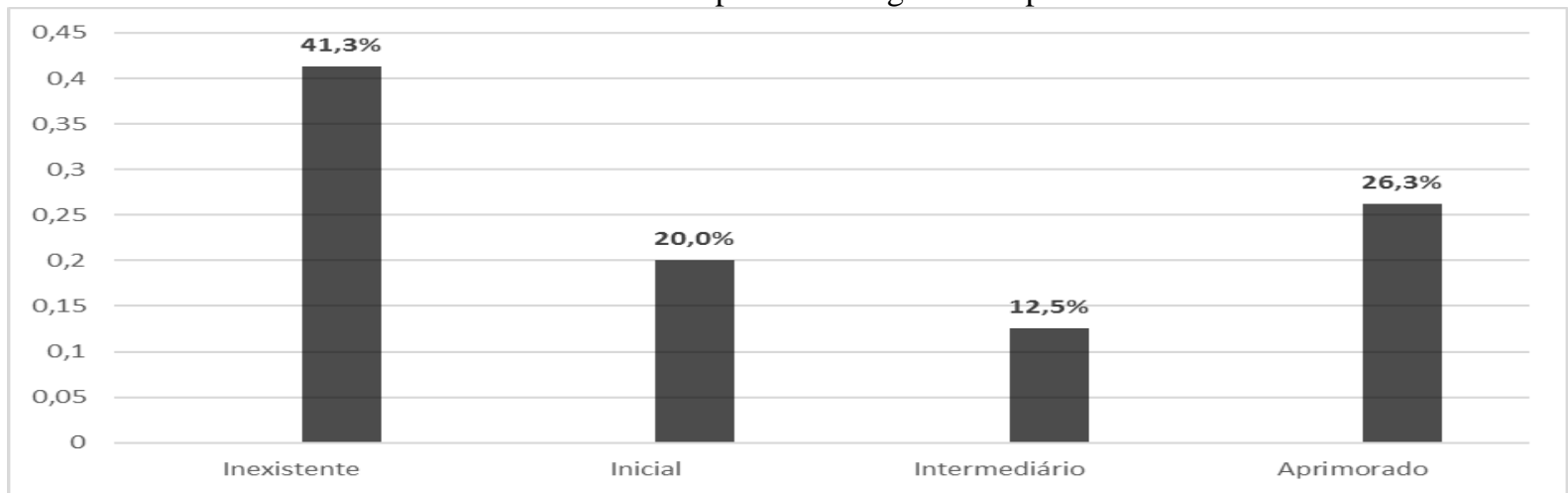

Fonte: Dados da Pesquisa. 


\section{CONSIDERAÇÕES FINAIS}

A partir do estudo, constatou-se que o problema suscitado pertinente ao sistema de carreira do quadro técnico administrativo das prefeituras municipais da Cantu de fato não produz resultados efetivos nos padrões estabelecidos pela área de Gestão de Pessoas, na busca pelo desenvolvimento profissional, como sugere o modelo gerencial, em razão basicamente do excesso de gasto com pessoal, conforme veremos.

Tal afirmação é sustentada pelas variáveis pesquisadas, que envolveu administração de cargos; planejamento de carreira e avaliação de desempenho; administração de salários, e; treinamento e desenvolvimento de pessoal, pois, embora as instituições públicas pesquisadas sustentem-se por estruturas normativas de hierarquia quanto ao quadro de pessoal, na prática acontece a meio termo, ou seja, a estrutura é formal, mas, as expectativas do servidor e consequente valorização não acontece em sua totalidade.

De forma geral, de acordo com o gráfico 2, infere-se que os municípios analisados estão com baixa capacidade de gestão, vez que em 41,3\% inexiste práticas capazes de modernizá-las ou profissionalizá-las no que se refere à área de pessoal, fator que prejudica a continuidade do serviço público e prestação de serviços com qualidade.

Dito isto, o objetivo do estudo de traçar uma análise do sistema de carreira dos Municípios da Cantu para verificar a importância atribuída ao servidor público municipal no que se refere à promoção na carreira, produziu resultados satisfatórios para a pesquisa, comprovando os problemas no poder público para com os critérios de valorização e desenvolvimento profissional.

Além disso, as evidências ratificam a hipótese e confirmam a justificativa quanto à importância e iminência de uma atuação mais estratégica por parte do gestor. A comprovação se dá no sentido de que os municípios analisados, em que pese quantificarem os recursos humanos necessários para enxugar a máquina, fazendo com que o suprimento de pessoas seja mais efetivo, ainda encontram-se imbuídos em práticas patrimonialistas, revestidas de vícios, resultando no engessamento no que se refere ao aspecto funcional, seja via concursos ou contratações comissionadas, práticas estas que causam certa dificuldade em revertê-las.

Assim, embora as instituições aleguem que o fator excesso de gasto com pessoal não é a principal razão de não haver promoções na carreira, os resultados de forma geral, 
direcionam para esta conclusão, já que ao menos metade delas manifesta certa dificuldade em criar oportunidades de promoção, e uma boa parte não consegue mantê-las em dia nem repor as perdas inflacionárias, levando a crer que se o excesso de gastos com pessoal não é a principal razão, contribui de forma significativa para o agravamento do cenário.

Tal entendimento se dá em razão do comprometimento destes índices, que para cumprir as determinações da LRF, impacta na concessão de aumento salarial e na reestruturação da carreira, necessitando primeiramente reduzir despesas com pessoal. A ação governamental não é totalmente falha, vez que atende alguns requisitos estabelecidos pela legislação que rege a área de pessoal como, por exemplo, a definição, estruturação, agrupamento e classificação de cargos, a falha se dá no sentido das oportunidades de promoção e desenvolvimento na carreira que não são efetivas e acaba desmotivando o servidor.

Neste sentido, Evans (1996) questiona "como desenvolver pessoas" e ao mesmo tempo responde: dando-lhes responsabilidades e poder de decisão, porém, depende das organizações o desenvolvimento de políticas apropriadas, e sem rede de influência (DAGNINO, 2009). Sem tais ações por parte do poder público, o investimento no pessoal e o desenvolvimento da capacidade de agir formada pelo conjunto de conhecimento, habilidade e atitude descrito por Zampier et al (2013) ficam comprometidos.

Assim, nesta fase mais recente da Gestão Pública é cristalino maiores investimentos no ativo mais importante da organização, oportunizando um sistema de carreira autêntico e efetivo. A sustentação poderá advir do controle interno, e uma sugestão para o problema poderia ser a implantação da gestão por competências a partir do investimento nas competências individuais resultando assim no desenvolvimento das competências institucionais.

Devido à amplitude e complexidade do tema, o estudo teve algumas limitações: dificuldade de acesso às informações nos sítios públicos, como por exemplo: telefone, email, etc., do departamento de pessoal; inércia por parte de alguns departamentos no que se refere à disponibilidade de participar da pesquisa; a aplicação dos resultados na prática pode ser de difícil execução, e; carência de artigos científicos publicados que abordam a temática de modo similar. Espera-se que a pesquisa possa fomentar outros estudos, como: pesquisa de satisfação dos servidores em relação à carreira, implantação de gestão por competências, ampliar o estudo do índice de gasto com pessoal, entre outros, que, dada sua 
importância, merecem análise de forma especial, possibilitando inclusive a transferência do método aqui utilizado para o contexto de outras instituições públicas ou associações de municípios de portes similares.

\section{REFERÊNCIAS}

ASSOCIAÇÃO DOS MUNICÍPIOS CANTUQUIRIGUAÇU. Disponível em: <http://www.cantuquiriguacu.com.br/>. Acesso em: nov. 2017.

BENDASSOLLI, Pedro F. Recomposição da Relação Sujeito-trabalho nos Modelos Emergentes de Carreira. RAE-Revista de Administração de Empresas. v. 49, n. 4, p.387-400, out-dez, 2009.

BRASIL. Constituição da república federativa do brasil. 41 ed. Brasília: Saraiva, 2008

BRASIL. Emenda constitucional $\mathrm{n}^{\mathrm{o}} 19$ de 04 de junho de 1998. Disponível em: <http://www.planalto.gov.br/ccivil_03/Constituicao/Emendas/Emc/emc19.htm> Acesso em: dez. 2017.

BRASIL. Lei complementar $\mathrm{n}^{\circ}$ 101, de 4 de maio de 2000. Lei de Responsabilidade Fiscal. Disponível em: <http://www.planalto.gov.br/ccivil_03/Leis/LCP/Lcp101.htm> Acesso em: nov. 2017.

BRESSER, Luiz C. P. Plano Diretor da Reforma do Aparelho do Estado. Brasília, 1995.

DAGNINO, Renato P. Planejamento estratégico governamental. Florianópolis: Departamento de Ciências da Administração /UFSC: CAPES: UAB, 2009.

DUTRA, Joel S. Administração de Carreira. Uma proposta para repensar a gestão de pessoas. São Paulo: Atlas, 1996.

EVANS, Paul. Carreira, Sucesso e Qualidade de Vida. RAE-Revista de Administração de Empresas, v. 36, n. 3, p.14-22, jul-set, 1996.

FILHO, F. de H. B. PESSÔA, S. de A. A carreira de professor estadual no Brasil: os casos de São Paulo e Rio Grande do Sul. RAP-Revista de Administração Pública. Rio de Janeiro 45(4): 965-1001, Jul./ago. 2011

JUNQUILHO, Gelson S. Teorias da administração pública. Florianópolis: Departamento de Ciências da Administração/UFSC. Brasília: CAPES: UAB, 2010.

KLEIN, Fabio A. MASCARENHAS, André O. Motivação, satisfação profissional e evasão no serviço público: o caso da carreira de especialistas em Políticas Públicas e Gestão Governamental. RAP-Revista de Administração Pública. Rio de Janeiro 50(1):17-39, jan./fev. 2016. 
MARCONI, Nelson. Políticas integradas de recursos humanos para o setor público. 2005. Biblioteca Virtual TOP sobre Gestión Pública. Disponível em: $<$ http://www.top.org.ar/ecgp/FullText/000000/MARCONI\%20Nelson\%20$\% 20$ Politicas\%20integradas\%20de\%20recursos\%20humanos. pdf $>$. Acesso em: $1^{\circ}$ fev. 2017.

MILKOVICH, George T.; BOUDREAU, John W. Administração de Recursos Humanos. São Paulo: Atlas, 2000. . Administração de Recursos Humanos. São Paulo: Atlas, 2010.

LONDON, M.; Stumph, S. Managing careers. Reading, MA: Addison-Wesley, 1982.

OLIVEIRA, José A. de. e MEDEIROS, Maria da P. M. de. Gestão de pessoas no setor público. Florianópolis: Departamento de Ciências da Administração/UFSC; Brasília: CAPES: UAB, 2011.

PARANÁ. Governo do estado do paraná. Secretaria da Administração e da Previdência. Portal do Servidor. Carreira. Disponível em: <http://www.portaldoservidor.pr.gov.br/modules/conteudo/conteudo.php?conteudo=91> Acesso em: 18 de mar. 2018.

PRIMAK, Irineu. STEFANO, Silvio. ANDRADE, Sandra M. de. ZAMPIER, Marcia A. Administração pública: a importância de uma carreira em uma universidade pública do estado do paraná. Revista de Carreiras e Pessoas (Recape). São Paulo, 2014.

SALM, José F.; MENEGASSO, Maria E. Os modelos de administração pública como estratégias complementares para a coprodução do bem público. Revista de Ciências da Administração, Florianópolis, p. 83-104, set. 2009.

STEFANO, Sílvio R. (Org.). Gestão de pessoas: fundamentos e aplicações. Guarapuava: Unicentro, 2011.

TACHIZAWA, Takeshy; FERREIRA, Victor C. P.; FORTUNA, Antônio A. M. Gestão com Pessoas. Uma abordagem aplica as estratégias de negócios. 2 ed. Rio de Janeiro: FGV, 2001.

TOLEDO, Junior Flávio C. de. e ROSSI, Sérgio Ciquera. Lei de responsabilidade Fiscal: comentada artigo por artigo. São Paulo: NDJ, 2001.

ZAMPIER, Marcia A.; BERNARDIM, Marcio L.; STEFANO, Silvio R. (Orgs.). Gestão de talentos. Guarapuava: Unicentro, 2013. 